\title{
No se lo digas a nadie ${ }^{1}$
}

\author{
Joyce Slochower, Ph.D., ABPP2 \\ Programa Postdoctoral de la Universidad de Nueva York
}

\begin{abstract}
Las violaciones de los límites sexuales -y quienes las cometen- son fantasmas que nos atormentan dentro ( $y$, por supuesto, fuera) del mundo psicoanalítico. Estas violaciones invaden casi todas las comunidades profesionales y repercuten mucho más allá de la díada analítica particular dentro de la cual ocurren. Las violaciones de los límites sexuales proyectan una gran sombra sobre nosotros; generan horror, ansiedad, curiosidad y a veces excitación. Nuestra necesidad de negar lo que sabemos y de proteger a los honorables mentores del escrutinio público nos ha llevado a un silencio colectivo tóxico. En general, permanecemos mudos públicamente, mientras que en privado lo hablamos mucho. Las destructivas consecuencias de "contar" lo sucedido generan una ansiedad que complica aún más nuestra experiencia, dando lugar a profundas negaciones (o escisiones): una expulsión casi total de la violación y de nuestra experiencia. En este artículo me pregunto por las dinámicas que generan nuestras complicadas respuestas a las violaciones de los límites sexuales y exploro su relación con nuestro ideal profesional, utilizando una experiencia personal para ilustrar algunos de estos problemas.
\end{abstract}

Palabras clave: violaciones de los límites sexuales, idealización, colusión, cotilleos, violador de límites

Sexual boundary violations - and their perpetrators - are ghosts that haunt us within (and of course outside) the psychoanalytic world. Reverberating well beyond the particular analytic dyad within which they occur, these violations invade nearly every professional community. Sexual boundary violations cast a long shadow over us; they generate horror, anxiety, curiosity, and sometimes excitement. Our need to deny what we know and to protect exalted mentors from scrutiny has led to a toxic collective silence; by and large, we have remained publically mute while engaging in plenty of private gossip. Anxiety about the destructive consequences of "telling" further complicates our experience and can result in disavowal-a near total foreclosure of the reality of the breach along with our experience of it. I query the dynamics driving our complex responses to sexual boundary violations and explore their collision with our professional ideal, using a personal experience to illustrate some of these issues.

Key Words: sexual boundary violations, idealization, collusion, gossip, boundary violator. English Title: Don't Tell Anyone.

\section{Cita bibliográfica / Reference citation:}

Slochower, J. (2018). No se lo digas a nadie. Clínica e Investigación Relacional, 12 (3): 419-435. [ISSN 1988-2939] [Recuperado de www.ceir.info] DOI: 10.21110/19882939.2018.120301

\footnotetext{
${ }^{1}$ Texto de la intervención de Joyce Slochower en el INSTITUTO DE PSICOTERAPIA RELACIONAL / ÁGORA RELACIONAL (Madrid) el 29 de Junio de 2018. Este trabajo se basa en otros presentados anteriormente en la Wounds of History Conference, New York University, en 2013; en el Israel Forum, Tel Aviv, Israel, en 2013; American Psychological Association Division 39 Spring Meeting, New York, NY, en 2014; y en la International Association for Relational Psychoanalysis and Psychotherapy, Sydney chapter, Sydney, Australia en 2016, y está parcialmente publicado en Psychoanalytic Psychology 2017, Vol. 34, No. 2, 195-200 0736-9735/17/\$12.00 http://dx.doi.org/10.1037/papo000082 @ 2017 American Psychological Association. Reproducido como texto de su conferencia, con autorización de la autora. Traducción al castellano de Mariana Salgado.

2 Joyce Slochower es Doctora en Psicología y Psicoanalista (individual y de parejas); vive y trabaja en Nueva York. Profesora y supervisora en el Programa Postdoctoral de la Universidad de Nueva York, del Steven Mitchell Center for Relational Psychoanalysis entre otros. Entre sus publicaciones Excessive Eating: The Role of Emotions and Environment (1983), Holding and Psychoanalysis: A Relational Approach (1996) y Psychoanalytic Collisions (2006). Contacto: 15 West $75^{\text {th }}$ St. 8B - New York, N.Y. 10023 Joyce.slochower@gmail.com Tel. 212-362-4437

CelR Vol. 12 (3) - Octubre 2018 ISSN 1988-2939 - www.ceir.info

@ Derechos reservados/Copyright de Clínica e investigación Relacional y los autores. Prohibida la reproducción total o parcial sin autorización expresa. Este material es para uso científico y profesional exclusivamente y puede contener información clínica sensible. Los editores no se responsabilizan de los contenidos de los autores. Dirigir las consultas sobre derechos y autorizaciones a ceir@psicoterapiarelacional.es
} 
Era una joven candidata (analítica) a principios de la década de 1980 cuando tuve mi primer encuentro con violaciones de los límites sexuales. Una buena amiga mía, en análisis con un respetado analista varón 20 años mayor que ella, me confesó que él se le había insinuado sexualmente de manera explícita. Ella rechazó tales propuestas, aunque continuó en tratamiento, permaneciendo en silencio tanto con él como sobre él.

Si es que esta experiencia la traumatizó, se lo dejó para sí misma. Su silencio me confundió. Yo no podía asimilar ni articular cómo me sentía con esto. En vez de eso, archivé lo que sabía y lo mantuve en un espacio aparte. Probablemente, pensé yo, esto fue un incidente aislado en la carrera de un analista ampliamente querido. ¿Qué ganaría creándole problemas a alguien que tantos admiraban? Parecía que no había forma de mantener su talento en tensión con sus transgresiones y yo contribuí a esto último.

Resulta que mi amiga estaba lejos de estar sola en esta experiencia. Comenzaron a aparecer rumores, algunos vagos y otros bastante específicos, sobre historias que mezclaban el horror con el placer lascivo. El analista de mi amiga, junto con otra persona estimada, habían violado las fronteras sexuales de supervisados (as) y pacientes. Décadas más tarde, nos enteramos de que estos no eran ni rumores ni hechos aislados.

Casi todos nosotros hemos tenido acceso a (o escuchado) cotilleos, y hechos, sobre violaciones de límites (sexuales y no sexuales) dentro y fuera de nuestra comunidad institucional particular. Sin embargo, solo un pequeño número de estas violaciones han sido objeto de escrutinio público; incluso cuando lo son, casi nunca se discuten abiertamente, y mucho menos se hacen públicos en foros más amplios. Muy a menudo, el evento se trata más como una historia espeluznante que como un fenómeno que requiere una seria exploración.

Las teorías psicoanalíticas se fundan en ideas sobre los elementos psíquicos de la sexualidad. Entonces, qué irónico, y qué sorprendente es que se hayan promulgado cruces fronterizos incestuosos desde nuestros comienzos profesionales. Si bien hay una gran cantidad de literatura sobre la dinámica del violador y la víctima (Celenza, 2007; Dimen, 2011; Gabbard \& Lester, 1995; Gabbard, Peltz, \& the COPE Study Group, 2001; Margolis, 1997; Pepper, 2014; Pizer, 2000; Sandler \& Godley, 2004), se ha escrito mucho menos sobre el impacto que tiene este fenómeno en la comunidad institucional. ¿Qué sucede, psicológicamente hablando, para aquellos de nosotros que no estamos directamente involucrados? ¿Qué hacemos con, y sobre, lo que sabemos?

Los psicoanalistas podemos representar una torre de Babel clínico/teórica en muchos aspectos, pero una cosa nos une: a pesar de nuestro compromiso de proteger a nuestros 
pacientes, los analistas han estado cometiendo violaciones de límites sexuales desde los comienzos de esta disciplina. Si bien estamos enormemente perturbados por estos eventos, hemos hecho poco para abordar el problema; de hecho, nos hemos confabulado para mantenerlo fuera de la vista, si no fuera de nuestra mente. Si bien no somos presa del tipo de contagio disociativo maligno del que habló Sue Grand (2000), tendemos a tratar con lo que no se puede abarcar retirándolo de nuestra consciencia.

Las violaciones de los límites sexuales -y sus responsables- son fantasmas que nos acechan dentro ( $y$, por supuesto, fuera) del mundo psicoanalítico. Loewald (1960), tomando prestado el término de Freud "fantasmas" (1900/1953) e indirectamente de Homero, notó que "Los fantasmas del inconsciente apresados por defensas, pero persiguiendo al paciente en la oscuridad de sus defensas y síntomas son liberados, cuando se les permite probar la sangre. A la luz del análisis los fantasmas del inconsciente son tratados y llevados al descanso como antepasados" (Loewald, 1960, p. 249).

No hemos sacado a la superficie, y mucho menos analizado, nuestros fantasmas. A diferencia de los antepasados que pueden descansar en paz, los fantasmas de las violaciones de los límites sexuales tienen un impacto que es a la vez insidioso, indescriptible y profundo (Kalb, 2015). Estos fantasmas flotan -no se metabolizan- en el borde de nuestras comunidades, coloreando nuestros sentimientos acerca de nuestra profesión, instituto y colegas (Margolis, 1997; Honig \& Baron, 2013). Periódicamente apareciendo en el encuentro clínico, las sombras tanto del violador como de la víctima se convierten en elementos no-yo que nos perturban, interrumpen e incluso nos descarrilan.

No es raro que las violaciones de los limites sexuales tiendan a repetirse a lo largo de las generaciones analíticas. Sus víctimas, como cualquier otra víctima de un trauma, son especialmente vulnerables a actuar, a la inversa, la agresión sufrida. Es frecuente que la víctima quede abandonada, sintiéndose culpable y avergonzada, en el proceso de metabolizar la experiencia. Es raro que haya un grupo de testigos que reconozca lo traumático de la experiencia, y mucho menos que tome medidas en nombre de la víctima contra el perpetrador.

Pero nuestras fallas en la comunidad psicoanalítica no reflejan una indiferencia colectiva. Lo que nos vuelve pasivos es nuestra incapacidad, casi absoluta, para abordar las violaciones sexuales. No sabemos qué decir, a quién contarle o qué hacer. Debido a que estamos profundamente perturbados, nos sentimos desamparados y a menudo inmovilizados. 
El motivo por el que quedamos tan confundidos es porque las violaciones de los limites sexuales suelen ser realizadas por aquellos con gran poder profesional. El violador tiene autoridad: incluso pudo haber sido un "gran" psicoanalista, alguien a quien hemos idealizadoํ. Al igual que el padre en la serie de televisión estadounidense de los 50, "Papá lo sabe todo", creímos (y queríamos creer) que él sabía todo. ¿Cómo pudo haber ignorado nuestro código de ética profesional, actuando como si las reglas no se aplicaran con él? Nos sentimos crispados y desmoralizados. Su comportamiento nos sacude y desarma nuestro ideal profesional, dejándonos no solo afligidos, sino también desilusionados ${ }^{2}$.

Nuestra necesidad de idealizar al violador hace difícil absorber los alcances de su infracción. Medio racionalizamos: quizás su genialidad terapéutica le permitió ignorar los límites sin comprometer su capacidad para sanar (Slochower, 2011). A lo mejor en verdad actuó en el mejor interés del paciente, al menos la mayor parte del tiempo.

Autorizar al violador a través de nuestra idealización conlleva un alto costo personal: nos obliga a abandonar nuestro propio sentido de agencia ética, una sensibilidad ética con consecuencias tanto a nivel personal como profesional: nos obliga a no nombrar lo que sabemos. Nos convertimos en cómplices, participantes pasivos en algo que aborrecemos. Una asimetría exagerada (Aron, 1996) que ata nuestras propias manos y nos hace más pequeños, menos sabios y menos conscientes de lo que usualmente somos (Grand, 2000), mientras que elevamos el estatuto del otro idealizado. Es cierto que el violador real es el principal responsable ético de lo que hace, pero lo facultamos con nuestro silencio. De este modo nuestra idealización tiene un punto débil perverso: nos ayuda a mantener la negación de lo que hemos visto y de lo que sabemos. Nos invita a participar de manera pasiva en la violación de los límites sexuales, convirtiéndonos en cómplices.

Sin embargo, no podemos prescindir de nuestras idealizaciones. Necesitamos creer que nuestros mentores y el campo del psicoanálisis son un todo. Nuestros ideales nos inspiran y sostienen frente a la incertidumbre clínica; nos dan parámetros para evaluarnos a nosotros mismos.

Queremos y necesitamos creer en nuestro potencial curativo y en el del psicoanálisis, en nuestra capacidad de dejar de lado el exceso de necesidad personal en el mejor interés de nuestros pacientes. Los ideales psicoanalíticos nos recuerdan la importancia de la ética profesional y la integridad, la autorreflexión, y la honestidad en nuestro campo, en general. En algunos aspectos, nuestros ideales representan una brecha entre los tipos de delincuencia que he discutido en otra parte (Slochower, 2006, 2014), y de lo que Hirsch (2008) denominó "dejarse llevar" en la contratransferencia"3. 
(Los ideales) Deben servir como una barrera para las violaciones de los límites sexuales y no sexuales. Pero por lo general no lo hacen. Nuestros ideales, de hacer algo, nos hacen casi imposible enfrentar el desborde y la vulnerabilidad al colapso. Frecuentemente la brecha entre nuestros ideales y la realidad nos silencia; nos invita a la compartimentalización, negación e incluso a la desautorización. "No es posible que haya tenido relaciones sexuales con el paciente, es un desagradable rumor realizado por aquellos que lo envidian". "No era paciente, solo era supervisada". "No fue para tanto, fue solo un hecho aislado". En otras ocasiones, encontramos formas más complejas (pero igualmente problemáticas) de racionalizar lo que sucedió: "A veces la gente realmente se enamora. El paciente tiene su misma edad y ambos están en la profesión; ambos tomaron una decisión madura y consciente para mover la relación hacia un ámbito diferente". 0 incluso, impactante en su cinismo / ingenuidad, decimos cosas como "Vamos. Tampoco es como si se la hubiese violado".

Cuando la evidencia del daño hace que este tipo de racionalizaciones sean imposibles, como cuando el analista es algunas décadas mayor que el paciente o cuando el paciente se derrumba o presenta una demanda, podemos mover la negación en una dirección diferente. Mantenemos nuestra idealización culpando -realmente patologizando- a la víctima y enfatizando la inocencia del analista y sus intenciones benignas: "En realidad, este paciente es muy límite, es increíblemente seductora; apuesto a que lo alucinó y convirtió su toque bondadoso en un momento sexual" o "Él pensó que la estaba ayudando y ella lo sedujo para poner en acto su historia de abuso; él es ingenuo pero en verdad es un buen tipo. Y ella es extraordinariamente autodestructiva".

A pesar de la negación implícita en estas idealizaciones (y de la denigración implícita de la paciente), con frecuencia hay, al menos, algo de verdad. Los pacientes que han sido victimas de abuso por lo general actúan su propia historia en la relación terapéutica. Esas dinámicas contribuyen a su desenlace sexual y hacen que, para nosotros, sea más fácil culparlos. A nuestra confusión emocional se le añade el hecho de que los analistas que rompen los límites profesionales raramente son culpables de un abuso frío y calculado. La mayoría probablemente no sean psicópatas ni estén del todo definidos por sus acciones; pueden ser escritores brillantes o con otros pacientes pueden realizar trabajos terapéuticos delicados y especializados. Los analistas, quienes también son vulnerables a la fantasía, a veces pierden la noción de su propia necesidad o deseo de intimidad, rescate o amor idealizado. Como Gabbard (2017) nos recordó, las violaciones sexuales suelen ser el punto final de un lento deslizamiento por una pendiente resbaladiza con un paciente en particular; no ocurre con todos los pacientes. ¿Deberíamos ennegrecer por completo 
el nombre y destruir la reputación de alguien que también reside fuera del ámbito de la falla analítica?

Nuestra necesidad de proteger el estatuto del infractor a menudo repercute en un nivel más abstracto, ya que el deseo de preservar un ideal profesional choca con la necesidad de llamar las cosas por su nombre. ¿Qué pasa si "contar" daña el lugar de nuestra comunidad en el mundo psicoanalítico en general? ¿Qué pasa si interrumpimos, incluso desarmamos, la experiencia de esos analizados, supervisados y estudiantes que, de hecho, fueron ayudados por el analista? Al declarar que el emperador no tiene ropa, ¿destruiremos nuestro reino?.

Para complicar aún más las cosas, denunciar puede ser contraproducente ¿Qué pasa si decir nombres desencadena un castigo excesivo por parte de los comités de ética y la comunidad en general (Celenza, 2007)? ¿Qué pasa si hacemos más mal que bien? ¿Y si somos castigados por decir, no por el perpetrador, sino que por aquellos que lo rodean $y$ quieren protegerlo? A menudo (aunque no siempre) el violador es alguien con poder profesional; tememos su capacidad (y la de sus seguidores) de tomar represalias. Estamos en silencio porque tenemos miedo. Incluso nuestra ansiedad puede hacernos dudar de lo que sabemos.

A estas ansiedades más personales se unen todo tipo de restricciones legales que nos limitan. En los Estados Unidos, la ley estatal define si alguien que no sea el pacientevíctima puede denunciar o no una violación sexual; en muchos estados, aquellos que "saben" a través de rumores no pueden iniciar una acción legal. Además, tanto el denunciante como el propio instituto son vulnerables a los juicios por difamación cuando se dicen los nombres; aquellos en posiciones de poder administrativo son silenciados por sus propios asesores legales.

Con frecuencia, nuestras manos están atadas; no hay nada concreto que podamos hacer con lo que sabemos o sospechamos. Asustados, temerosos de causar problemas, sintiéndonos impotentes, nos volvemos dudosos. ¿Estamos seguros? Después de todo, no estuvimos allí. ¿Qué pasa si estamos equivocados? Impotentes, frustrados, dejamos de lado lo que sabemos.

Cuando la realidad se vuelve innegable y nos enfrentamos con lo que no podemos excluir, nuestra idealización se quiebra, y es reemplazada por una amarga desilusión. "Es un incompetente". "Está perdiendo el juicio". "Piensa con su pene". De manera efectiva excomulgamos al analista, lo expulsamos psíquica y literalmente. En parte, hacemos esto porque la conducta del analista ha sido reprensible y merecedora del destierro. Pero creo que a menudo otra dinámica funciona aquí: cuando denigramos al analista, 
simultáneamente encontramos una manera de proteger nuestra idealización reubicándola en otra parte: "Él no es un verdadero analista". "No es mi héroe; en cambio, $X$, nunca se comportaría de esta manera. Es él a quien admiro". A menudo, aquellos que cometen violaciones de límites justifican sus acciones convocando una teoría clínica que racionaliza su rechazo al encuadre analítico convencional. Así lo requieren la inhibición sexual o emocional, y la vulnerabilidad y necesidad del paciente. La violación a menudo comienza cuando el analista responde al historial de trauma del paciente y a la intensidad de sus necesidades primarias, sintiendo que debe tomar medidas extraordinarias. Gabbard (2016) describe cómo la contención física no sexual puede gradualmente transformarse en una relación sexual cuando el analista se encuentra atrapado, sumergido por el poder de su deseo sexual (y el de su paciente) con la intención de salvar al paciente. Las fantasías de rescate se funden con la omnipotencia y agresión disociadas, precipitando un deslizamiento gradual hacia la transgresión sexual, un deslizamiento aparentemente respaldado por la teoría del analista sobre la acción clínica.

Algunos han sugerido (por ejemplo, Bernstein, 2003) que algunas teorías en particular (por ejemplo, la teoría de las relaciones objetales) invitan a las infracciones de límites debido al poder de la metáfora materna reparadora, la cual lleva al analista hacia la actuación ${ }^{4}$. Sin embargo, estoy convencida de que cualquier teoría clínica se puede mal interpretar de esta manera; ningún modelo representa una protección impermeable o un refugio teórico seguro contra las violaciones.

Aquí presento dos ejemplos dramáticos en los que se utilizaron otras teorías clínicas para justificar violaciones de límites. Estos ejemplos no pretenden ser representativos de este fenómeno: reflejan ejemplos particularmente atroces y flagrantes de actuación sexual. Con mayor frecuencia, las violaciones de límites sexuales evolucionan de forma fluida a partir de una creciente implicación emocional con un paciente. Pero estos ejemplos particulares ilustran cómo el analista puede hacer un mal uso de la teoría para justificar una brecha en los límites.

Un analista freudiano masturbaba a su joven paciente mujer de manera regular hasta el orgasmo con el pretexto de activar su "libido muerta". El empleo teórico de la pulsión fue usado de manera perversa como una racionalización para su actuación sexual. La grandiosidad de este analista, respaldada por su estatuto en la comunidad, lo protegía del escrutinio, y la censura. Otra paciente, en análisis con un interpersonalista, contó cómo frecuentemente su analista, después de llevarla a almorzar, la besaba y tocaba. El analista creía que la libre interacción social/sexual ayudaría a su paciente tímida y autocrítica a sentirse mejor consigo misma, y a despertar sus deseos sexuales. La paciente 
estaba consciente de sentirse incómoda y cohibida, aunque contenta por el lugar especial que ocupaba en la vida de su analista. Años más tarde pudo reconocer cuán traumatizantes habían sido estas experiencias.

Así como ninguna teoría analítica justifica este tipo de violaciones de límites, ninguna nos protege completamente de su atracción. De hecho, Sue Grand (2017) sugiere que nuestras teorías pueden estar implicadas en nuestra mala conducta: al privilegiar en la terapia la importancia de la transferencia erótica, creamos un ambiente "excesivamente seductor" que con demasiada facilidad hace que la situación se deslice en la dirección de la seducción real.

Si es que estos deslices no se esconden es porque en nuestra comunidad se encuentra el deseo y la disposición a ver y nombrar estas infracciones. Sin embargo, es rara la comunidad psicoanalítica que haya abordado eficazmente este problema con sus miembros, sin importar el mundo psicoanalítico más amplio. Si bien los infractores a veces se ven obligados a abandonar su instituto, la mayoría de las veces se restablecen en otro lugar. Sus despedidas tienden a mantenerse en silencio; la comunidad puede murmurar cotilleos, pero los hechos son escasos.

En uno de mis institutos seguimos sin nombrar a un querido mentor, ahora fallecido hace mucho tiempo, quien es ampliamente conocido por haber cometido múltiples violaciones de límites sexuales. Admiramos su visión y escritura; no sabemos cómo conciliar su brillantez con su mala conducta. Es aún más difícil nombrar a los infractores que siguen vivos y trabajando entre nosotros. Y así, cuando salieron a la luz las recientes violaciones de límites en uno de mis institutos, predominaron los intensos cotilleos y el silencio público. En parte, esto se debe a que la administración (del instituto) está legalmente limitada: el temor a las demandas y otras consecuencias financieras hace que los abogados insistan en una total discreción.

Sin embargo, aunque las restricciones sean inevitables, se engaña, se manipula, a la comunidad profesional en general y a los candidatos en formación, en particular. En última instancia, el elemento transgresor se convierte en parte de nuestro legado profesional, alojado en una especie de inconsciente colectivo psicoanalítico.

Sin embargo, no estamos silenciados solo por restricciones legales. Las preocupaciones sociales y personales también nos amordazan. Nos preocupamos por los rumores, por causar problemas o meternos en problemas, por herir a un colega, a su paciente o a un amigo. A menudo los cotilleos susurrados son nuestro único alivio o liberación. Encontramos un Otro, o algunos otros, con quienes compartir lo que sospechamos o conocemos. Pero cotilleo es una palabra débil para describir esto. El equivalente hebreo 
- lashón hara (habla malvada) - tal vez capta con mayor precisión los malos sentimientos (e intenciones) muy cargados que encarnan este tipo de cotilleos. En lugar de servir como un envoltorio emocional dentro del cual contener, procesar y abordar directamente los sentimientos perturbadores, los cotilleos intensifican nuestra sensación de angustia. (EI cotilleo) no proporciona ninguna oportunidad para la exploración o procesamiento emocional; nos deja perturbados en lugar de aliviados.

Los cotilleos se producen casi exclusivamente entre amigos o en grupos muy pequeños; los grupos más grandes usualmente excluyen este tipo de intercambio. De hecho, en una pequeña clase de 10 (asistentes) en la que soy profesora se debatieron enérgicamente dos violaciones sexuales, una anterior y otra actual, mientras todos evitamos nombrar a los miembros infractores de la facultad. Varias personas declararon que sería difamatorio hacerlo (aunque todos sabíamos de quiénes estábamos hablando y que estos eran hechos y no rumores). La conversación tomó otro curso y se dirigió hacia un transgresor de un instituto diferente cuya historia había sido publicada en la prensa. Era seguro nombrarlo; él era "otro", ni personalmente amado (idealizado) ni poderoso en nuestro instituto.

Cuando se trata del nuestro, permanecemos mudos públicamente. Nuestro silencio parece proteger a nuestra comunidad, pero no es así. Sino que sostiene una especie de ilusión o engaño grupal en donde se nos hace casi imposible, a nosotros como individuos y como instituciones, contener y metabolizar las violaciones sin hacer más daño a nuestra autoimagen profesional ni a nuestra identidad grupal. A nuestra familia. Y paradojalmente, aunque intente exponer esta dinámica aquí, puedo actuarla simultáneamente: describo eventos realmente perturbadores, pero no nombro los institutos a los que me refiero o aquellos sobre quiénes estoy hablando. Te dejo, al lector, adivinando. ¿Confundo más que aclarar? ¿Desperté la curiosidad y la ansiedad, perpetuando así el problema cuando intento descomprimirlo? ¿̇nadvertidamente creo aún más testigos silenciosos y silenciados?

Estoy tentada de nombrar un nombre, de romper activamente esta colusión. Tendría que ser un nombre seguro, el nombre de una persona fallecida o alguien ya nombrado en la prensa, alguien que no podría demandarme a mí o a mi institución. En un nivel, hacerlo sería aliviar; estaría nombrando al elefante bajo la mesa.

Pero en otro nivel, me sentiría más perturbada que aliviada. Nombrar al perpetrador podría tener un impacto destructivo en sus pacientes anteriores, aquellos de los que no abusó, en sus colegas y estudiantes. ¿Qué ganaría al nombrar a alguien que ya no es un peligro para sus pacientes? Siguen siendo un peligro esos a los que no puedo nombrar. 
Los perpetradores que están vivos y activos son los que realmente me tienen preocupada. Incluso aquí, nombrar nombres es problemático.

En el proceso de identificar a algunos, estaría dejando a otros fuera, creando así algunos chivos expiatorios mientras inadvertidamente protejo a otros transgresores. Parece no haber escapatoria ${ }^{5}$. Hay algo más que considerar: ¿Cómo va usted, el lector, a experimentar todo esto? ¿Qué pasa si usted mismo fue víctima o testigo de una violación sexual? ¿Qué pasa si quiebro su renegación, si es su analista, colega o amigo quien fue o es un violador o una víctima? ¿Sentirás enfado con el infractor por violar tu confianza? ¿Te sentirás expuesto ya que su secreto está parcialmente desenmascarado? ¿Culpa porque has guardado silencio al respecto? ¿Vergüenza porque no denunciaste tu abuso o el abuso del que fuiste testigo? ¿Celos y dolor (por no haber sido elegido como un paciente o confidente "especial")? Y si fuiste o eres "sólo" un testigo, ¿cuán molesto tienes derecho a estar? Después de todo, no te pasó a ti.

Cuando comencé a trabajar en este artículo, ingenuamente asumí que me dirigiría a lectores espectadores y testigos, aquellos que vivían fuera de las violaciones reales. Solo más tarde me di cuenta de que algunos lectores podrían haber cometido (o podrían estar cometiendo) una violación de límites. ¿Este artículo abrirá un espacio reflexivo, te dejará espacio para explorar la dinámica detrás de lo que hiciste o estás haciendo? ¿O te alejaré, dejándote más a la defensiva y más enojado que nunca? Cuando presenté versiones anteriores de este artículo en conferencias, me preocupaba que un grupo grande no pudiera contener los sentimientos perturbadores que este material podía evocar. Los grupos grandes no proporcionan ni un sentido de cohesión ni seguridad emocional; los participantes necesitan limitar cuánto se exponen personalmente.

Además, en un grupo grande la sensación de cohesión puede verse amenazada por la divulgación de las violaciones de los límites sexuales. De hecho, estas discusiones grupales solían evocar recuerdos de violaciones de límites que habían ocurrido en la comunidad y, a veces, a algún miembro del grupo en particular. Sorprendentemente, muchos informaron que habían "olvidado" todo sobre la ruptura de los límites hasta ese momento; algunos lidiaron con angustia significativa en un contexto que no parecía del todo seguro.

Publicar un artículo podría resolver el problema de trabajarlo en grupo. Leemos solos y, a lo mejor, podemos metabolizar solos. No necesitamos tratar con el Otro, al menos no al principio. Pero con la soledad surgen otros riesgos. Enfrentamos nuestras sospechas o nuestros secretos en el espacio privado. Estamos aislados de aquellos que podrían compartir nuestra experiencia; somos vulnerables a una microforma ${ }^{6}$ de la soledad que 
acompaña la historicidad y responsabilidad ausente del trauma (Grand, 2000). Esa soledad perpetúa nuestro silencio colectivo y, una vez más, nos invita a renegar.

La renegación es una defensa formidable, ya que, con lo que deja de lado, refleja la magnitud de la perturbación traumática. $Y$ esto lo sé desde mi interior, porque me encontré con mi propia renegación mientras escribía este artículo. Es una historia que nunca reprimí o disocié, pero que se alojó en un espacio tan cubierto que aparentemente su impacto fue olvidado.

Aproximadamente 25 años después de que terminé mi primer análisis, descubrí que mi antigua analista había dejado a su marido por una paciente. Mi ex analista y yo todavía estábamos en contacto, y yo (bastante ingenuamente) intenté comunicarle mi angustia. Como era de esperar, ella no acogió esta conversación y se puso extremadamente enfadada y a la defensiva.

La interacción fue difícil y decepcionante, pero fue lo que sucedió a continuación lo que representó una brecha en los límites. Unos días más tarde recibí un mensaje telefónico muy largo y hostil de la pareja (a quien no conocía) de mi ex analista. En ella, no sólo defendió a mi ex analista, sino que dejó en claro que sabía mucho sobre mí y utilizó ese conocimiento para atacarme personalmente. Su maldad me dejó sacudida. Claramente, mi ex analista había compartido información personal sobre mí con su pareja. La llamada telefónica de represalia y amenaza de su compañera evocó una mezcla de daño, indignación y vulnerabilidad cuando traté de digerir el hecho de que mi analista había traicionado mi confianza.

Me molesté menos de lo que podría haber estado, probablemente porque esta relación de trabajo tenía décadas de antigüedad y había llegado a ver a mi ex analista de una manera difuminada más que idealizada. Aún así, me sorprende que, hasta que escribí este artículo, no me había dado cuenta de que se había cometido, en mi contra, una segunda violación de límites. Mi analista primero traicionó a su paciente-amante, pero también traicionó a sus otros pacientes y ex pacientes, incluyéndome a mí. Ella quebró mi ideal profesional dos veces al romper las fronteras sexuales con su propia paciente y luego cuando no respetó la naturaleza privilegiada de nuestra relación. Había logrado dejar de lado el hecho de que había sido testigo y víctima. Qué difícil de metabolizar, incluso 30 años después. Los pacientes antiguos que se dan cuenta, pero que no son víctimas de violaciones de límites, quizás están en una posición similar a la de un niño no abusado cuyo hermano está siendo maltratado. Aunque a menudo él o ella no tienen otra opción emocional que guardar el secreto, el elemento traumático periférico se asimila a un nivel procedimental donde se pudre y perturba. 
A veces, nuestro silencio comunica un residuo sociopolítico: es el horror de ser informantes, adultos chismosos. En los Estados Unidos, nuestra reticencia, en parte, refleja la sombra traumática de la era McCarthy. Nos avergonzamos de las implicaciones de señalar con el dedo. De hecho, muchos de nosotros estamos identificados con la posición del Otro y con la autonomía ética inherente a esa postura. Aunque no es una autonomía que nos mueva fácilmente hacia la denuncia de irregularidades.

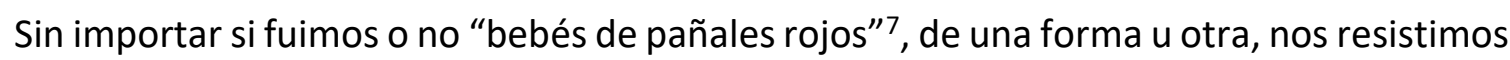
a convertirnos en informantes. El silencio se alimenta de preocupaciones reales, personales y políticas. Nos queremos proteger a nosotros mismos y a nuestra comunidad del escándalo. No queremos causar problemas, unirnos al "establishment" o colaborar con los poderes de turno.

Del mismo modo, hay más fuentes de conflicto personal que nos impiden alzar la voz. ¿Nuestra ansiedad (a menudo inconsciente) sobre nuestra propia maldad y destructividad hace que denunciar parezca un acto de agresión, en vez de hacerlo en nombre de la víctima y de una comunidad más amplia? Después de todo, ¿quién de nosotros nunca ha cometido una violación de límites ni se permitió una fantasía sexual sobre un paciente? ¿Quién nunca ha albergado fantasías hostiles sobre un colega, o se ha preocupado por su impacto negativo en el otro? Nombrar a un transgresor estimula nuestro propio sentimiento de "mal-analista" (Epstein, 1999), nuestra ansiedad asociada y la culpa sobre nuestra propia mala conducta, por mínima que sea y cualquiera que sea su particularidad.

Aquí hay otro elemento complicado: a pesar de que la literatura psicoanalítica haya reconocido desde hace tiempo la presencia de lo erótico en la contratransferencia, nuestras propias fantasías están peligrosamente al borde de la actuación cuando contemplamos la realidad de las violaciones sexuales. Si bien estas violaciones nos molestan, un elemento de carga sexual a menudo coexiste con esa angustia. La mayoría de nosotros nunca hemos participado en cruzar los límites sexuales, pero apostaría a que casi todos nosotros hemos tenido momentos en los que deseábamos poder hacerlo. Pensar o hacer chismes acerca de la actuación sexual de un colega es inquietante, pero a la vez puede ser excitante.

El colega que promulga lo prohibido nos brinda la oportunidad de experimentar indirectamente lo indebido, al tiempo que refuerza nuestro sentido subjetivo de pureza. ¿Registramos una doble respuesta de horror y una especie de excitación perversa? ¿Nos separamos, ubicando la sexualidad allá donde no amenaza nuestro propio sentimiento de analista bueno? 
Sospecho que tanto la vergüenza como el placer están mezclados aquí. Una respuesta al trauma que se funde con una excitación erótica más común y nos hace sentir, a la vez, avergonzados y afectivamente elevados. El cotilleo nos permite experimentar la carga erótica de una historia impactante, mientras permanecemos por encima del conflicto. ¿Es nuestro cotilleo una especie de masturbación emocional, estimulante pero carente de un clímax o una finalidad que contenga y calme las cosas?

Ciertamente nuestra emoción no es sencilla. En parte está formada, o impulsada mejor dicho, por sentimientos subyacentes de horror erótico (Kumin, 1984), duelo, identificación con la víctima, rabia y por una sensación de impotencia. Pero en paralelo a esto, o quizás en respuesta a ello, nos resulta difícil renunciar al placer perverso inherente a guardar silencio y cotillear sobre estos secretos eróticos.

Estoy sugiriendo que nosotros en nuestra comunidad hemos fallado en restringir las violaciones porque estamos implicados en ellas. En oscurecer lo que se sabe, nos enfrentamos a un peligro diferente, al sentimiento de que somos cómplices, de que, en parte, hemos colaborado tanto como individuos como en cuanto comunidad profesional Me parece que, en el fondo, nuestros complejos sentimientos sobre las violaciones de los límites reflejan nuestra poderosa necesidad inconsciente de retener un ideal analítico perfecto. Ese ideal impide la duplicidad y, por lo tanto, es vulnerable a la fragmentación. $\mathrm{Si}$ queremos superar este impasse, debemos sostener la posibilidad de que un comportamiento profesional verdaderamente reprensible pueda coexistir con la capacidad de un buen trabajo analítico y brillantez intelectual.

¿Podemos encontrar una manera de crear nuestra propia versión de la Comisión Sudafricana de Verdad y Reconciliación (M. Moskowitz, comunicación personal, 17 de abril de 2013)? Allí, víctimas de violencia indescriptible enfrentaron a sus abusadores. La posibilidad de una justicia restaurativa fue creada cuando el daño fue completamente reconocido, y en algunas circunstancias, se concedió amnistía a los acusados ${ }^{8}$.

Les propongo un deseo/fantasía: que nosotros, como comunidades o institutos psicoanalíticos, creemos un sistema de justicia restaurativa tanto para las víctimas como para los perpetradores de violaciones de límites. Que comencemos a acercarnos de manera directa pero privada a nuestros colegas cuando creemos que pueden haber cometido o podrían cometer violaciones de los límites; y que hagamos lo mismo con aquellos que sospechamos que son víctimas.

Las víctimas de graves violaciones de límites a menudo escriben sobre sus experiencias en ensayos y libros (véanse especialmente Dimen, 2011 y Deutsch, 2014), al tiempo que 
protegen el nombre y el instituto del infractor u otro entorno en el que se produjo la infracción. Este es, creo, un primer paso hacia el tipo de proceso restaurativo en el que estoy pensando. Pero no va lo suficientemente lejos.

¿Podemos imaginarnos creando un espacio protegido y seguro en el que dicho proceso pueda ocurrir públicamente? ¿En el que perpetradores podrían reconocer lo que sucedió como un primer paso hacia la rehabilitación? ¿Podríamos crear una atmósfera reflexiva más que punitiva dentro de la cual la víctima y el perpetrador pudieran hablar entre ellos y reconocer el daño causado? ¿En la que leyes estatales y asociaciones tales como la Asociación Americana de Psicología otorguen absolución de la acusación en los casos en que haya una confesión total, remordimiento y reparación? ¿Podemos siquiera entender ese proceso separado de la acción legal y el destierro?.

No estoy segura. Pero incluso para siquiera pensar en hacer esto, debemos reconocer lo que sabemos. En voz alta. Hablar. Juntos. Esto significa aceptar que algunos de nuestros héroes analíticos fueron y son también violadores. Sabiendo que nosotros, que no hemos violado las fronteras sexuales, cometemos infracciones analíticas pequeñas pero perturbadoras (Slochower, 2003, 2014).

Los psicoanalistas tenemos mucho de qué enorgullecernos y mucho de qué avergonzarnos. ¡Qué irónico que nosotros, que asumimos el valor clínico de la paradoja y la complejidad emocional, tengamos tantas dificultades para mantener nuestros ideales con flexibilidad! Con frecuencia nos vemos obligados a negar lo no-ideal porque la amenaza traumática de la desidealización es insoportable. Si vamos a enfrentar nuestro silencio y su dinámica, si queremos abordar la experiencia de las víctimas, los perpetradores y los testigos e intentar cualquier tipo de reparación, debemos hablar juntos sobre lo que sabemos, sentimos y tenemos miedo de decir. Necesitamos revisar nuestra relación con nuestros ideales personales y profesionales y hacer las paces con las limitaciones de esta profesión. Honig y Barron (2013) nos dieron un modelo a seguir en su descripción sobre la respuesta de un instituto a las violaciones de límites sexuales. Barbara Pizer (2000) propuso que para protegernos de estas violaciones necesitamos consultar continuamente a lo largo de nuestra vida analítica. Y ciertamente, este monográfico ${ }^{9}$ abre el diálogo y pone el problema en el dominio público, donde se puede abordar.

Dudo mucho que alguna vez tengamos éxito en poner fin a las violaciones de los límites sexuales o no sexuales, pero podríamos encontrar maneras de abordar su impacto en la comunidad profesional, y de abordar nuestra participación en ellas si estuviésemos 
menos compelidos a sostener una visión rígida de nuestro trabajo y de nosotros mismos. Es hora, ¿no creen?

\section{REFERENCIAS}

Aron, L. (1996). A meeting of minds: Mutuality in psychoanalysis. New York, NY: Analytic Press.

Bernstein, J. W. (2003). Analytic thefts: Commentary on papers by Joyce Slochower and Sue Grand. Psychoanalytic Dialogues, 13, 501-511. http://dx.doi.org/10.1080/10481881309348753

Celenza, A. (2007). Sexual boundary violations: Therapeutic, supervisory and academic contexts. Lanham, MD: Aronson.

Deutsch, R. A. (2014). Traumatic ruptures: Abandonment and betrayal in the analytic relationship. New York, NY: Routledge.

Dimen, M. (2011). Lapsus linguae, or a slip of the tongue? A sexual violation in an analytic treatment and its personal and theoretical aftermath. Contemporary Psychoanalysis, 47, 3579. http://dx.doi.org/10.1080/00107530.2011.10746441

Epstein, L. (1999). The problem of the bad-analyst-feeling. Contemporary Psychoanalysis, 35, 311-325. http://dx.doi.org/10.1080/00107530.1999.10747036

Freud, S. (1953). The interpretation of dreams. In J. Strachey (Trans. \& Ed.), The standard edition of the complete psychological works of Sigmund Freud (Vol. 4, p. 553). London, UK: Hogarth. (Original work published 1900)

Gabbard, G. O. (1995). The early history of boundary violations in psychoanalysis. Journal of the American Psychoanalytic Association, 43, 1115-1136.

http://dx.doi.org/10.1177/000306519504300408

Gabbard, G. O. (2016). Boundaries and boundary violations in psychoanalysis (2nd ed.). Arlington, VA: American Psychiatric Association.

Gabbard, G. O. (2017). Sexual boundary violations: A thirty-year retrospective. Psychoanalytic Psychology, 34(2): 151-156.

Gabbard, G. O., \& Lester, E. (1995). Boundaries and boundary violations in psychoanalysis. New York, NY: Basic Books.

Gabbard, G. O., Peltz, M. L., \& the COPE Study Group on Boundary Violations, Committee on Psychoanalytic Education. (2001). Speaking the unspeakable: Institutional reactions to boundary violations by training analysts. Journal of the American Psychoanalytic Association, 49, 659-673. http://dx.doi.org/10.1177/00030651010490020601

Grand, S. (2017). Seductive excess: Erotic transformations, secret predations. Psychoanalytic Psychology, 34(2):208-214.

Grand, S. (2000). The Reproduction of Evil. Hillsdale, NJ: The Analytic Press.

Hirsch, I. (2008). Coasting in the countertransference. New York, NY: Routledge. 
Honig, R. G., \& Barron, J. W. (2013). Restoring institutional integrity in the wake of sexual boundary violations: A case study. J. Amer. Psychoanal. Assn., 61, 897-924.

Kalb, M. (2015). Ghosts in the consulting room: Reluctant ancestors. Contemporary Psychoanalysis, 51, 74-106. http://dx.doi.org/10.1080/00107530.2015.985905

Kumin, I. (1984). Erotic horror: Desire and resistance in the psychoanalytic situation. International Journal of Psychoanalytic Psychotherapy, 11, 3-25.

Loewald, H. W. (1960). On the therapeutic action of psycho-analysis. International Journal of Psychoanalysis, 41, 16-33.

Margolis, M. (1997). Analyst-patient sexual involvement: Clinical experiences and institutional responses. Psychoanalytic Inquiry, 17, 349-370.

http://dx.doi.org/10.1080/07351699709534131

Pepper, R. S. (2014). Emotional incest in group psychotherapy. London, UK: Rowman \& Littlefield.

Pizer, B. (2000). The therapist's routine consultations: A necessary window in the treatment. Psychoanalytic Dialogues, 10, 197-207. http://dx.doi.org/10.1080/10481881009348531

Sandler, A. M., \& Godley, W. (2004). Institutional responses to boundary violations: The case of Masud Khan. International Journal of Psychoanalysis, 85, 27-43.

http://dx.doi.org/10.1516/LP8G-5A70-9FFR-U62Q

Slochower, J. (2003). The analyst's secret delinquencies. Psychoanalytic Dialogues, 13, 451-469. http://dx.doi.org/10.1080/10481881309348751

Slochower, J. (2006). Psychoanalytic collisions (1st ed.). Hillsdale, NJ: Analytic Press.

Slochower, J. (2011). Analytic idealizations and the disavowed: Winnicott, his patients, and us. Psychoanalytic Dialogues, 21, 3-21. http://dx.doi.org/10.1080/10481885.2011.545317

Slochower, J. (2014). Psychoanalytic collisions (2nd ed.). Hillsdale, NJ: Analytic Press.

Original recibido con fecha: $\quad 30 / 04 / 2018 \quad$ Revisado: 26/06/2018 Aceptado: 30/10/2018

NOTAS:

\footnotetext{
${ }^{1}$ Para que sea más simple, me refiero al violador como "él" (o en masculino). Aunque ocurran violaciones de los límites sexuales entre analista mujer y paciente hombre o en parejas analíticas del mismo sexo, la gran mayoría de estas transgresiones ocurren en constelaciones analista hombre-paciente mujer siendo en este ámbito en el que me concentro.

${ }_{2}$ De todos modos, esto no siempre es verdad. Algunos violadores son conocidos por ser corruptos, incluso psicópatas. Su incumplimiento puede molestarnos, nos hace sentir cínicos y amargados, pero no nos sorprende ni altera nuestro ideal profesional (ver Gabbard, 2017).

${ }^{3}$ N.de T-: La autora, cita a Hirsch, que usa "coasting": aprovechar la inercia del movimiento o del viento para navegar

${ }^{4}$ Las perspectivas de reparación materna han sido especialmente criticadas por invitar a cruzar los límites desde que Wynne Godley publicó su artículo sobre su experiencia con Masud Khan.
} 
${ }^{5}$ En una discusión sobre su propia experiencia como paciente, Dimen (2011) consideró la dinámica de las violaciones sexuales y las poderosas fuerzas que silencian al paciente, al analista y al instituto. Ella, como yo, se abstuvo de nombrar al violador.

${ }^{6} \mathrm{~N}$.de T.: Reproducción micro-fotográfica en película o papel de un manuscrito, mapa u otro documento

${ }^{7} \mathrm{~N}$. de T. Hijos de padres miembros del partido comunista de Estados Unidos

${ }^{8}$ A partir de 1995, la Comisión Sudafricana de Verdad y Reconciliación brindó a las víctimas la oportunidad de describir públicamente su experiencia. Aquellos que han cometido abusos contra los derechos humanos también pueden solicitar la amnistía para su enjuiciamiento a cambio de reconocer sus acciones. Amnistía fue otorgada a aquellos que dijeron la "verdad completa" y cuyos crímenes fueron "motivados políticamente" (por supuesto, se trata de evaluaciones subjetivas).

${ }_{9}$ N. de T.: Publicado en Psychoanalytic Psychology 2017, Vol. 34, No. 2 